\title{
Simulation and Application of Algorithms CVRP to Optimize the Transport of Mineral Metallic and Nonmetallic by Rail to Export Level
}

\author{
Edna Cruz ${ }^{1}$, Alberto Ochoa ${ }^{2}$, José Alberto Hernández Aguilar ${ }^{3}$, Eliud De La Cruz ${ }^{1}$ \\ ${ }^{1}$ Instituto Tecnológico Superior de Naranjos, Veracruz, Mexico \\ ${ }^{2}$ Maestría en Cómputo Aplicado, UACJ, Ciudad Juárez, Mexico \\ ${ }^{3}$ FCAeI, Universidad Autónoma del Estado de Morelos, Morelos, Mexico
}

\begin{abstract}
Metallic and nonmetallic minerals produced at the State of Puebla, for convenience, can be transported in containers by train to a seaport cargo to be exported to other countries; for transporting minerals by railways, it must analyze which is the most optimal route to bring the product, taking into account various factors involved through each route in order to get a greater benefit for the transportation of minerals by train. This article compares two metaheuristic algorithms applied to Capacitated Vehicle Routing Problem (CVRP), in order to determine which algorithm gives better optimization solutions that help to make the best route for the transfer. As a final result, the implementation of an Ant Colony optimization algorithm was more successful in the runtime that a Genetic Algorithm; because it is slow to find an optimal solution among all generations.
\end{abstract}

Keywords: Metallic and nonmetallic, Export, Container train, Seaport, Metaheuristic Algorithms, Capacitated Vehicle Routing Problem (CVRP).

\section{Introduction}

The mining sector is one of the main sources of economy in Mexico, where the industrial sector, which provides social benefits that put Mexico in the main destination for investment in mineral exports in developed in 24 of the 32 states of the Republic Latin America and the fourth worldwide [1].

Mexico is among the top 10 in the production of 18 minerals [1]; it ranks second in the production of metallic minerals, the exploitation of silver and bismuth; fifth in lead; sixth in zinc, molybdenum and cadmium; and thirteenth place in iron production worldwide. In addition to exploiting non-metallic minerals, in which ranks second as a producer of fluorite, fifth in diatomite, sixth in barite, graphite and plaster, and eleventh place in feldspar, according to INEGI, 2014, explain in [4]. 
The state of Puebla is located in the east central area of Mexico and is strategically located within four physiographic regions; Neo Volcanic Axis, the Sierra Madre del Sur, the Sierra Madre Oriental and the Gulf Coastal Plain. This makes the state a major producer mostly of non-metallic minerals [2].

Table 1. Volume of mining production 2012- 2013 in the state of Puebla (tons).

\begin{tabular}{|c|c|c|}
\hline MINERALS & 2012 & 2013 \\
\hline \multicolumn{3}{|l|}{ METALLIC } \\
\hline Iron & $6,925 \mathrm{t}$ & $6,925 \mathrm{t}$ \\
\hline \multicolumn{3}{|l|}{ NON-METALLC } \\
\hline Limestone & $5,220,082 \mathrm{t}$ & $4,437,070 \mathrm{t}$ \\
\hline Sand & $4,292,000 \mathrm{t}$ & $3,651,563 \mathrm{t}$ \\
\hline Gravel & $2,007,008 \mathrm{t}$ & $1,705,957 \mathrm{t}$ \\
\hline Calcite & $1,567,678 \mathrm{t}$ & $1,506,767 \mathrm{t}$ \\
\hline Clay & $555,000 \mathrm{t}$ & $471,750 \mathrm{t}$ \\
\hline Cast & $258,980 \mathrm{t}$ & $220,133 \mathrm{t}$ \\
\hline Feldspar & $352,308 \mathrm{t}$ & $138,279 \mathrm{t}$ \\
\hline
\end{tabular}

Documentary Management Control and Strategic Indicators, Ministry of Economy, National Institute of Statistics and Geography, S.H.C.P.

Minerals that the state of Puebla exploits are minerals such as feldspar, Mexico exports it mainly to Venezuela, United States, Colombia and Chile, the plaster is exported to countries: United States, Ecuador, Costa Rica and Venezuela. Inside the exploitation of metallic minerals export of iron is characterized to countries such as Hong Kong, Japan, the United States and Canada. To carry out the export of these minerals from Puebla, it requires subsequent transfer to a nearby seaport, since most of the products exported by our country are transported by sea, due to the high load capacity and adaptability to transport all kinds of products $[2,3]$.

\section{Problem to Resolve}

Minerals like Iron, feldspar and gypsum exploited by the state of Puebla, are on the list of major minerals exported our country [2]; so as the need to exploit the mining sector of the State of Puebla to transport their minerals by railways to a nearby seaport where they can be exported. To do this is necessary to consider various factors that influence the transfer from Puebla to the seaport in order to find the best route for transporting minerals.

\section{Justification}

In the railway system in Mexico we can find intermodal railways corridors for maritime type where each route has its weight restrictions. 

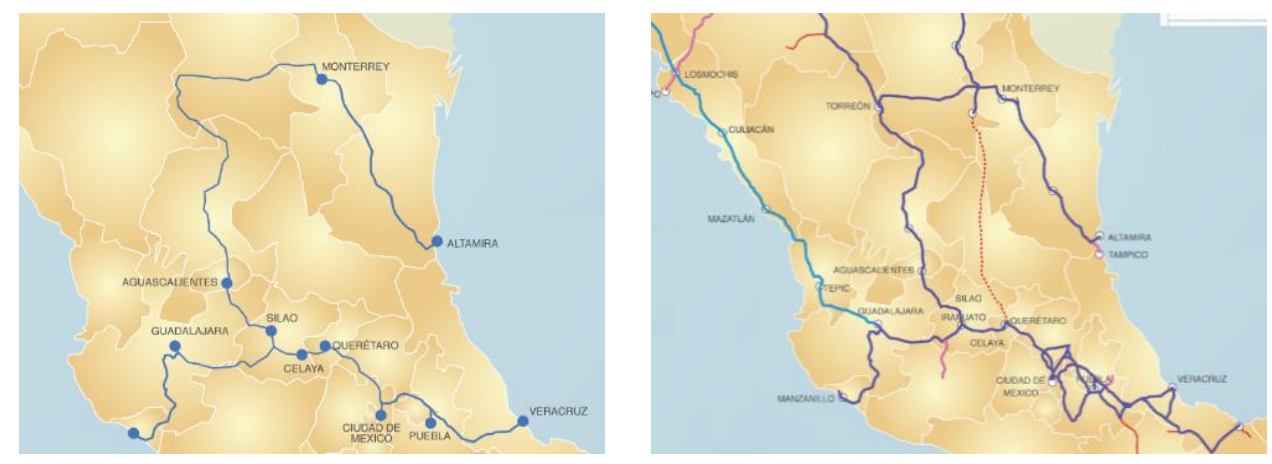

a) Intermodal maritime corridors. b) Railways classified by weight capacity.

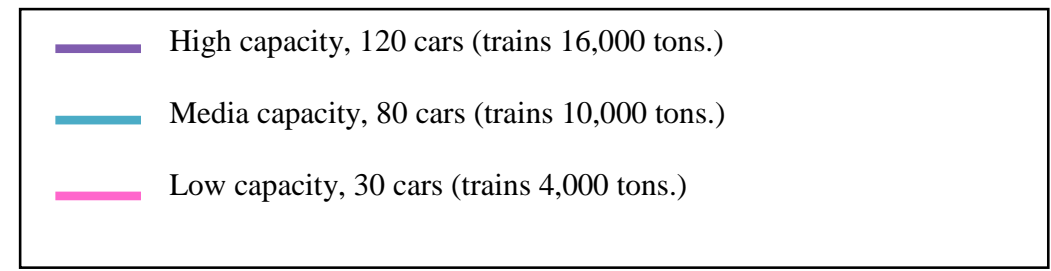

Fig. 1. Railways with maritime intermodal corridors and symbology weight capacity on lines [4].

In this investigation will be compared the routes from the train station in Puebla to the station near the seaport in Veracruz Port by train railways and the second route to the train station at the seaport of Altamira, Tamaulipas; by metaheuristics techniques taking into account the characteristics of minerals to be transported, in this case: Iron, Feldspar and Cast to choose the right type container train to use. In the course of the two routes, the train passes through different stations to which we will call nodes; with the help of algorithms, routes will be analyzed to compare their benefits.

Table 2. Characteristics of metallic and nonmetallic minerals.

\begin{tabular}{|c|c|c|}
\hline $\begin{array}{l}\text { METALLIC } \\
\text { MINERAL }\end{array}$ & TECHNICAL DATA. & USES \\
\hline Iron. & $\begin{array}{l}\text { It is soft, with a metallic sheen, } \\
\text { of steely gray to black. It corrodes } \\
\text { in air humid conditions or elevated } \\
\text { temperatures that causing an } \\
\text { oxidation reaction. }\end{array}$ & $\begin{array}{l}\text { Steel, coating , chemicals, } \\
\text { agrochemicals, pharmaceuticals, } \\
\text { cosmetics, paints, water treatment, } \\
\text { construction, refining, electrical, } \\
\text { electronics, textiles, ceramics, } \\
\text { glass, transport, mining, } \\
\text { agriculture, among others. }\end{array}$ \\
\hline
\end{tabular}




\begin{tabular}{|c|l|l|}
\hline $\begin{array}{c}\text { NON- } \\
\text { METALLIC } \\
\text { MINERALS }\end{array}$ & TECHNICAL DATA & \multicolumn{1}{|c|}{ USES } \\
\hline Feldspar. & $\begin{array}{l}\text { They belong to a group of } \\
\text { minerals forming aluminum } \\
\text { silicates combined in three forms: } \\
\text { potassium, sodium and calcium. } \\
\text { Its color can range from white to } \\
\text { colorless and completely melted at } \\
1,530^{\circ} \mathrm{C} \text {. }\end{array}$ & $\begin{array}{l}\text { As aggregate in glass, ceramics, } \\
\text { pottery, enamels for ceramics, } \\
\text { white ceramics, paints, coatings, } \\
\text { plastics, rubber, sealants, } \\
\text { adhesives, welding electrodes, } \\
\text { abrasives, substitutes. }\end{array}$ \\
\hline Plaster & $\begin{array}{l}\text { It is a dehydrated calcium } \\
\text { sulfate (CaSO4 2H20), presented } \\
\text { in tabular crystals peel able sheet, } \\
\text { generally colorless }\end{array}$ & $\begin{array}{l}\text { Construction, } \\
\text { agriculture, chemistry, writing } \\
\text { chalks, ceramics, medicine, dental, } \\
\text { food, mining works, foundry, water } \\
\text { treatment, paper, paintings, } \\
\text { ornaments. }\end{array}$ \\
\hline
\end{tabular}

Market 2014. General Mining Coordination profile. Directorate General of Mining Development.

According to the characteristics of the mineral, we implemented the wagon called nacelle, specialized to transport goods as ore, coal, metals, scrap, etc. [4].

Table 3. Characteristics of the car used for transporting Fierro, Feldspar and Plaster mineral [4].

\begin{tabular}{|c|c|}
\hline \multicolumn{2}{|c|}{ Nacelle bulk } \\
\hline Length & 15.8 meters. \\
\hline $\begin{array}{c}\text { Length with } \\
\text { couplings }\end{array}$ & 17.4 meters \\
\hline Height & 2.87 meters. \\
\hline Capacity & $\begin{array}{c}90 \text { a } 100 \\
\text { tons }\end{array}$ \\
\hline $\begin{array}{c}\text { Net Weight Without } \\
\text { Charge }\end{array}$ & 29.7 Tons \\
\hline
\end{tabular}

\section{$4 \quad$ Methodology}

The logistics involved in the transport of minerals by rail for export can be modeled by CVRP (Capacitated Vehicle Routing Problem) with metaheuristic techniques to analyze a series of routes that indicate which algorithm is suitable to adapt to each route optimizing transportation time and feasibility of it. In the following figures we show the maritime intermodal corridors to compare. 


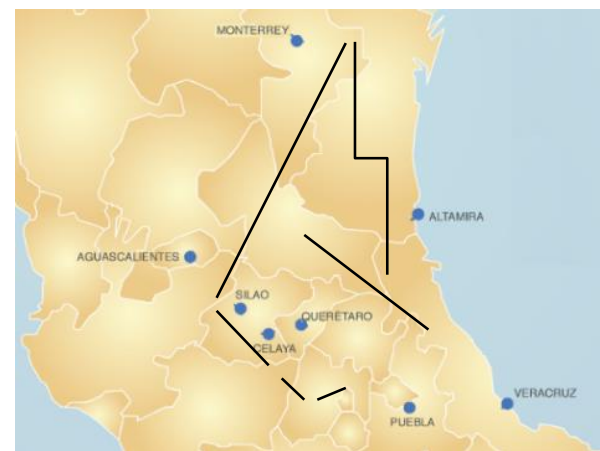

Route 1

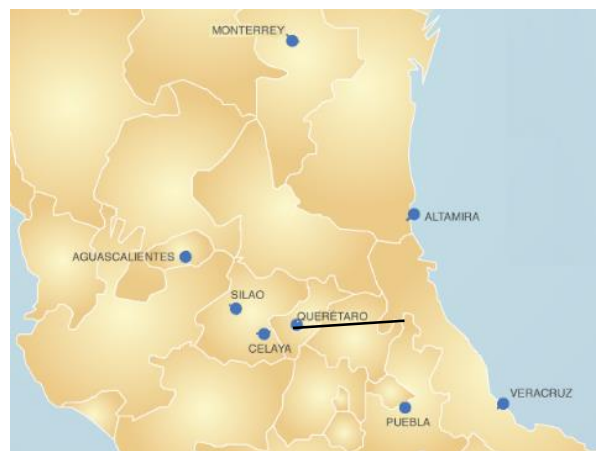

b) Route 2

Fig. 2. Routes a1 y b2 of maritime intermodal corridors to seaport.

In the literature it is mentioned that the optimization model CVRP, is used to determine the optimal routes for distribution of the limited load transportation to different geographical locations; It is an optimization problem NP- Hard type related to the Bin Packing Problem (BPP) when assigning loads to vehicles and also a Traveling Salesman Problem (TSP) that suggests the best route to follow [5].

In our case to analyze, it will be a starting point passing through different nodes to reach the seaport where the trainload is exported. For each issue, special restrictions are presented and as a result, it has been developed variants of VRP in order to obtain a better approximation most adaptable solution for each case. To compare the performance and optimization of each route will address the metaheuristic techniques reported in the literature for the vehicle routing problem with limited load.

\subsection{Genetic Algorithms (GA)}

Genetic algorithms are a class of evolutionary algorithms suitable for search and optimization problems where the main objective is to find a set of parameters that minimize or maximize an adaptive function; these algorithms operate on a population or set of solutions presented as binary strings or chromosomes. The function of the executed algorithm is to cross of individuals with greater ability to improve the population and eliminate individuals of lesser capacity, to find the best chromosome that is the solution of the problem $[6,7]$. The evolution of the population is performed with the application of genetic operators: selection, recombination and mutation.

In the literature there are some basic concepts to better understanding of genetic algorithms [6]:

- Chromosome: binary string representing an individual or solution, where each element in the chain is called gene. 
- Population: infinite set of chromosomes.

- Fitness: criterion that assesses the quality of a chromosome. A higher fitness, better solution and more likely to survive and transmit their characteristics to their offspring.

- Crossing: operation by which new offspring are produced from two parent chromosomes randomly selected.

- Mutation: operation where selected at random and change one or more genes on chromosome; it occurs with low probability.

An example taken from works of Sait and Youssef (1999), a genetic algorithm is defined as follows [6]:

Be $P=\left\{x^{1}, x^{2}, \ldots\right\} \subseteq \Omega$ the population.

While not stopping criterion is met:

Select as parents $\left\{x^{i}, x^{j}, \ldots\right\} \in P$ with probability proportional to $a\left(x^{i}\right)$ y $a\left(x^{j}\right)$

Parents crossing $\left\{x^{i}, x^{j}\right\}$ to generate the set $\mathrm{O}$ of $\mathrm{k}$ children

$O=\left\{x_{1}^{i, j}, x_{2}^{i, j}, \ldots, x_{k}^{i, j}\right\}$

For each child generated:

Generate mutation probability $P_{m}$

Do that this child enters to $\mathrm{P}$ with likely fitness.

If the child enters to $P$, do while

Randomize, with probability inversely proportional to the fitness, an element that leave $\mathrm{P}$, to be replaced by the new element.

End

End

End

Differences can occur between genetic algorithms when are adapted to a problem of optimization that tries to attack, because the parameters that are handled are not always the same, as well as there are basic fundamentals that genetic algorithms can be presented as representation and adaptive function, Selection Methods where the proportional selection comes, the selection algorithm by Ranking, tournament selection method; recombination operator and mutation. 


\section{Genetic Algorithm for TSP}

These algorithms applied to the TSP, in execution represent a solution as a sequence of nodes through permutations $(1, \ldots, n)$ while operators crossover and mutation may generate $n$-tuples that are not permutations. This is why it is important to define the crossover and mutation operators during encoding.

\subsection{Ant Colony Optimization (ACO)}

The metaheuristics algorithms of Ant Colony Optimization (ACO) were inspired by the behavior of real ant colonies by their structural organization and behavior that allows them to have good communication. Ants on their way from the starting point to the food supply, according to studies, pheromones are deposited on the ground leaving a trail to the rest of the colony; when more is the concentration of ants on a route, the greater the likelihood that another ant follow. This type of algorithms where a set of actors who take the role of "ants", work together as a colony and aims to indicate the best route to follow through pheromones.

The ant colony optimization gives various solutions by iterative procedures where each artificial colony casts a solution at each iteration, respectively until an end condition. The first such algorithm was applied to the traveling salesman problem (TSP) to obtain optimal results $[8,9]$.

\section{Travelling Salesman Problem (TSP) applied to Ant Colony Optimization (ACO)}

Ants provide solutions probabilistically with pheromones that are track; for the case of TSP the following formulas represent one rule to follow:

$$
p_{i j}^{k}(t)=\frac{\left[\tau_{i j}(t)\right]^{\alpha} \cdot\left[\eta_{i j}\right]^{\beta}}{\sum_{l \in N_{i}^{k}}\left[\tau_{i l}(t)\right]^{\alpha} \cdot\left[\eta_{l j}\right]^{\beta}} \text { With } j \in N_{i}^{k},
$$

where $p_{i j}^{k}(t)$ is the probability that an iteration $t$ algorithm, the ant $k$, currently located in the city $i$, choose the city $j$ as next stop. $N_{i}^{k}$ it is the set of cities not yet visited by the ant k. $\tau_{i j}(t)$ is the cumulative amount of pheromone on the arc $(i, j)$ of the network in iteration t. $\eta_{i j}$ is the heuristic information for which in the case of TSP, the inverse of the distance between the cities is used $\mathrm{i}$ and j. $\alpha$ and $\beta$ are two parameters of the algorithm that can be edited [9]. 


\subsection{Design of experiment}

The optimization algorithms based on Ant Colony are intended to represent various agents using random methods, while sharing information routes that are traveled.

In genetic algorithms it is simulated genetic evolution where in each generation are selected the fittest and are crossed to generate better-adapted descendants; considering that mutations are also generated in the process.

The following tests will be done with the corresponding algorithms to define which algorithm is best suited to the route optimization solution.

\section{Testing by Genetic Algorithm}

With a genetic algorithm executed by a Java applet, testing for route optimization are performed in the first test was conducted between 10 nodes that simulate the cities featured in the journey by train from Puebla to the port of Altamira. In the second test simulate 7 nodes representing the number of stations that are in the path of the state of Puebla to the port of Altamira.

\section{Test 1 by Genetic Algorithm for TSP:}
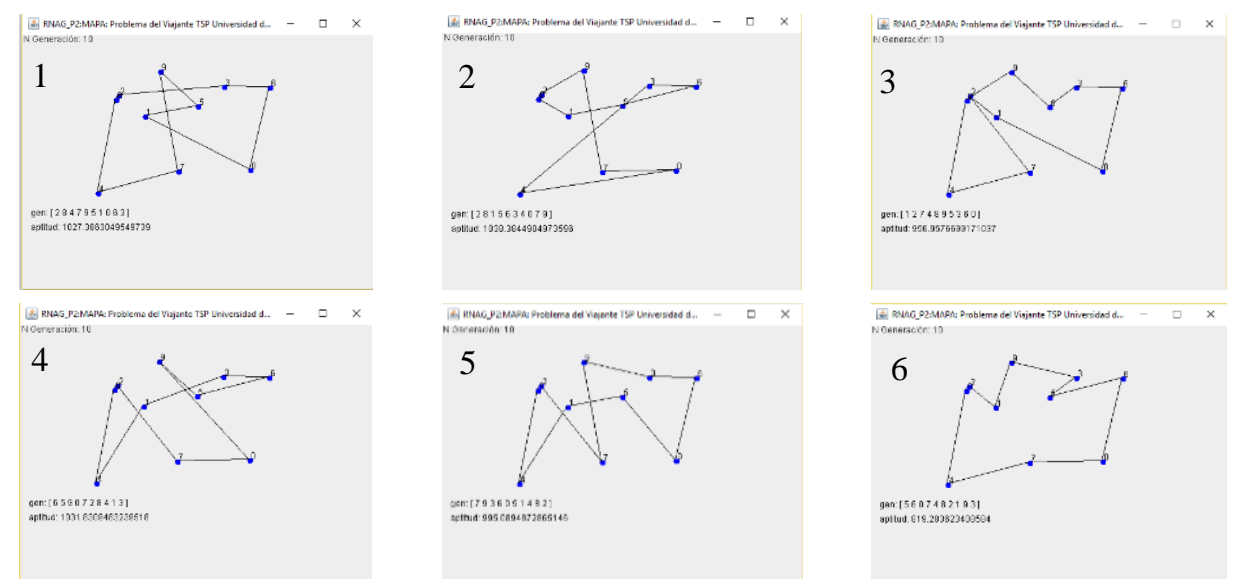

Fig. 3. Simulation screens of train traveling with 10 nodes using the Genetic Algorithm for TSP with a subprogram in java [10].

In the test parameters 1 , the simulation of ten nodes are with mutation probability of $10 \%$ , the probability of crossing $60 \%$ and a maximum number generations of 10 . Six tests which showed different routes to reach the optimum were made. 
Test 2 by Genetic Algorithm for TSP:
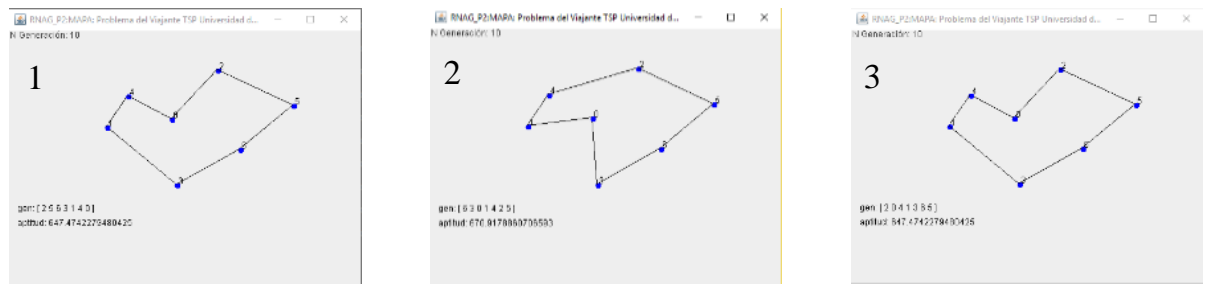

Fig. 4. Simulation screens of train traveling with 7 nodes using Genetic Algorithm for TSP with a subprogram in java

In this second test, only the number of nodes were modified to visit, just as with a population size of eleven, mutation probability $10 \%$, probability of crossing with $60 \%$ and the maximum number of generations of 10 .

\section{Testing by Ant Colony Optimization Algorithm}

With an ACO algorithm for TSP executed on a Java applet, two tests performed, where the first presents one route with 10 nodes representing cities that appear in the journey by train from Puebla to the port of Altamira. In the second test are 7 nodes representing the number of stations that exist in the path of the state of Puebla to the port of Altamira, they were simulated.

\section{Test 1 by Ant Colony Optimization algorithm for TSP:}

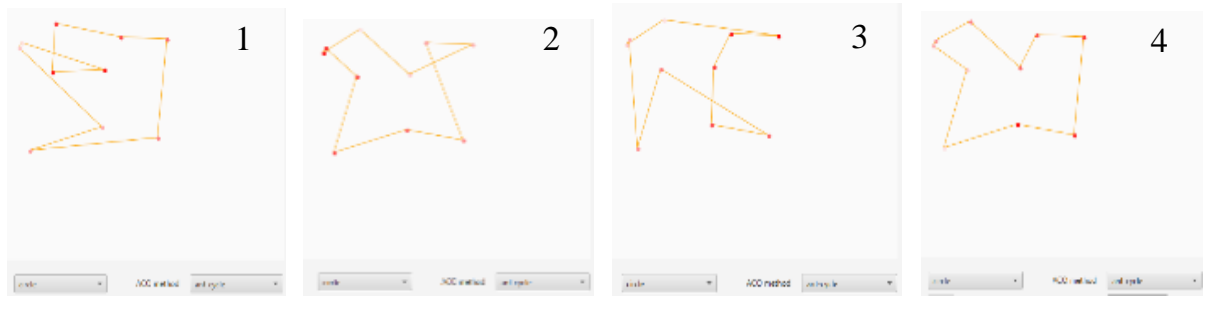

Fig. 5. Simulation screens train travel with 10 nodes using the algorithm Ant Colony Optimization for TSP with Java applet [11].

Tests conducted with 10 nodes representing cities that are in the path of the train from Puebla to the port of Altamira. Pheromone initial value on each line of 2.00 and ants value of 2.00 to select the next node. 
Test 2 by Ant Colony Optimization algorithm for TSP:

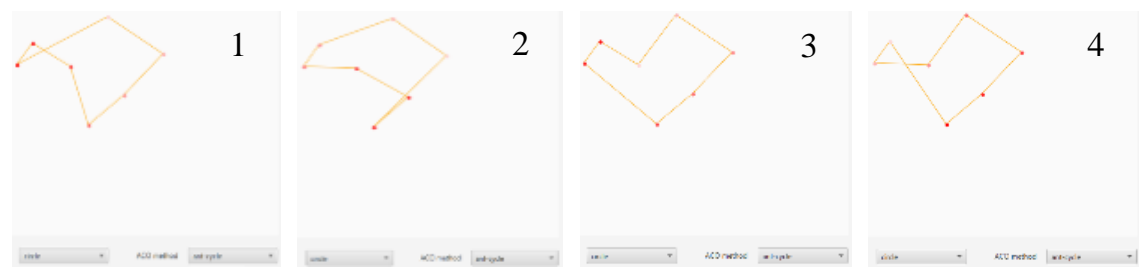

Fig. 6. Simulation screens, train travel with 7 nodes using the algorithm Ant Colony Optimization for TSP with a subprogram in java.

Tests conducted with 7 nodes representing the stations that are in the path of the train from Puebla to the port of Altamira. Pheromone initial value on each line of 2.00 and a value of 2.00 for ants to select the next node.

\section{$5 \quad$ Results}

To compare the efficiency of two algorithms, two tests were conducted, the first was performed with a map of 10 nodes of which the location is the same for the different executions. In the second test it was performed with a map with 7 nodes, where they remained in the same location for each run.

Table 4. Results shown in the execution of the AG and ACO algorithms for Travelling Salesman Problem, Own source made with data obtained with the implementation of algorithms in java applets $[10,11]$

\begin{tabular}{|c|c|c|c|c|c|c|}
\hline \multirow{2}{*}{ Algorithm } & E1 & E2 & E3 & E4 & E5 & E6 \\
\hline & \multicolumn{6}{|c|}{ Tests with 10 nodes } \\
\hline AG & $\begin{array}{l}\text { Route } \\
1\end{array}$ & $\begin{array}{l}\text { Route } \\
2\end{array}$ & $\begin{array}{l}\text { Route } \\
3\end{array}$ & $\begin{array}{l}\text { Route } \\
4\end{array}$ & $\begin{array}{l}\text { Route } \\
5\end{array}$ & $\begin{array}{r}\text { Route } \\
\text { optimal }\end{array}$ \\
\hline $\mathrm{ACO}$ & $\begin{array}{l}\text { Route } \\
1\end{array}$ & $\begin{array}{l}\text { Route } \\
2\end{array}$ & $\begin{array}{l}\text { Route } \\
3\end{array}$ & $\begin{array}{c}\text { Route } \\
\text { optimal }\end{array}$ & & \\
\hline \multicolumn{7}{|c|}{ Tests with 7 nodes } \\
\hline AG & $\begin{array}{c}\text { Route } \\
\text { optimal }\end{array}$ & $\begin{array}{r}\text { Route } \\
\text { optimal }\end{array}$ & $\begin{array}{c}\text { Route } \\
\text { optimal }\end{array}$ & & & \\
\hline $\mathrm{ACO}$ & $\begin{array}{l}\text { Route } \\
1\end{array}$ & $\begin{array}{l}\text { Route } \\
2\end{array}$ & $\begin{array}{l}\text { Route } \\
3\end{array}$ & $\begin{array}{c}\text { Route } \\
\text { optimal }\end{array}$ & & \\
\hline
\end{tabular}

In the first test between 10 nodes with Genetic Algorithm for TSP, it was observed that five executions were carried out before finding the optimal route and with the second test between seven nodes, genetic algorithm was more effective to provide the optimal route in the first test.

In the first test with 10 nodes using the ant colony algorithm, it was observed that three executions were carried out before finding the optimal route proving to be more efficient 
than GA algorithm. With the second test between seven nodes, 3 tests were also performed before displaying the optimum route.

\section{$6 \quad$ Analysis and Discussion}

In the algorithm Ant Colony Optimization by Ant cycle model; the ants represent the train carrying minerals that are dispersed among the nodes representing the cities that exist between the state of Puebla and Altamira. With the application of an algorithm of this kind, it is privileged by the local update of pheromones used to detect the busiest and most convenient routes for transport.

The genetic algorithm, its optimization technique is based on the evolution to random selection of the most optimal routes to carry out the transport, by creating new generations where again the most suitable route is chosen to create a new generation with the nearest solutions; in this way it is like in every generation are left the most optimal routes.

\section{$7 \quad$ Conclusions and Future Research}

Each optimization problem contains certain specific parameters; to implement an optimization algorithm for some problems is necessary to identify the components that carry the same, for choosing which metaheuristic technique is closer to solution. In conclusion, an algorithm of Ant Colony Optimization it is more adaptable for providing solutions to Travelling Salesman Problem, because this approach shows is good to find the routes closest to go, in less runtime. For the genetic algorithm, when exist fewer nodes on the route, yields better results; however, as more nodes or cities are added and increases the complexity, the ACO algorithms have better runtime.

This paper presents two TSP algorithms, the optimization algorithms Ant Colony and Genetic Algorithms, in order to analyze which is best algorithm that can adapt to transportation of minerals by railways destined to two important seaports in Mexico to export. In future work they could be analyzed the loading and unloading time with the algorithms discussed in this paper, as well as analyzes the nodes where it is convenient to exchange load at a station that is on the train route.

\section{References}

1. The importance of mining in Mexico. Available at : http://www.industriaminera mexicana.com/2013/02

2. Mexico, D. F., Salazar, D. Q.: National Institute of Statistics and Geography.

3. Bravo-Diaz, M., Maritima, I.: How to Export seaborne.

4. Ferromex. Available at: http://www.ferromex.com.mx

5. Orrego-Cardozo, J. P.: Solution to the problem of vehicle routing with limited capacity "PTRC" through heuristic scanning and the implementation of the genetic algorithm Chu-Beasley (2013) 
6. Gonzalez-Vargas, G., González-Aristizabal, F.: Metaheuristics applied to vehicle routing. A case study: Part 1: formulation of the problem. Engineering and Research, 26(3), pp. 149-156 (2006)

7. Valencia, E.: Optimization through genetic algorithms. In: Annals of the Institute of Engineers of Chile, 109(2), pp. 83-92 (1997)

8. Aparicio-Guirao, D.: Application of ant algorithms for solving a problem balancing robotic assembly lines (2012)

9. Boats, L., Rodriguez, V., Alvarez, M. J., Robusté, F.: Algorithm based on ant colony optimization by solving the problem of freight from multiple sources to multiple destinations. Santander, Spain (2002)

10. Arceti, A.: Traveling Salesman Problem (Genetic Algorithm). Available at: https://soporte900. wordpress.com/2011/11/13/proproblema-del-viajante-tsp/

11. Birger, M.: Ant Colony Optimization Demo. Available at : https://github.com/kusha/ant-colony 